\title{
Venous Thromboembolism: An Unusual Presentation of Pulmonary Tuberculosis
}

Nishan K. Purayil 1, 2, 3 , Jaseem Sirajudeen ${ }^{1,4}$, Khaled M. Al Arbi ${ }^{1}$, Mohamed A. Baghi ${ }^{5}$, Muhammad Zahid 6

1. Internal Medicine, Hamad Medical Corporation, Doha, QAT 2. College of Medicine, Qatar University, Doha, QAT 3. Internal Medicine, Weill Cornell Medicine-Qatar, Doha, QAT 4. Internal Medicine, Qatar University, Doha, QAT 5. Internal Medicine, Hamad General Hospital, Doha, QAT 6. Medicine, Hamad Medical Corporation, Doha, QAT

Corresponding author: Nishan K. Purayil, nishankp@live.com

\section{Abstract}

Tuberculosis is a leading cause of death due to infectious etiology worldwide. Myriad presentations and multisystem involvement of the disease can make the diagnosis extremely challenging. Venous thromboembolism is an uncommon entity in tuberculosis. The prevalence of venous thromboembolism is reported to be $1.5-3.4 \%$. The etiology of thrombosis could be multifactorial. All the elements of Virchow's triad can be present in these patients. This case report is about a patient presenting with deep vein thrombosis (DVT) and pulmonary embolism (PE), who was subsequently diagnosed with active pulmonary tuberculosis.

Categories: Internal Medicine, Infectious Disease

Keywords: tuberculosis, deep vein thrombosis (dvt), pulmonary embolism (pe), virchow's triad

\section{Introduction}

Despite the global efforts to control tuberculosis (TB), the burden of this disease remains high and is still a leading cause of death due to infectious etiology [1]. TB presents with various pulmonary or extrapulmonary manifestations. Venous thromboembolism, that is deep vein thrombosis (DVT) and pulmonary embolism (PE) are uncommon in TB, with a reported prevalence of around 1.5-3.5\% [2]. The occurrence of both in the same patient is rarer. Even though DVT and PE belong to the same spectrum of a disease, the former entity is three times more prevalent than the latter in patients with TB [3].

Review began 03/12/2021 Review ended 03/20/2021 Published 03/24/2021

๑) Copyright 2021

Purayil et al. This is an open access article distributed under the terms of the Creative Commons Attribution License CC-BY 4.0., which permits unrestricted use, distribution, and reproduction in any medium, provided the original author and source are credited.

\section{Case Presentation}

A 49-year-old gentleman from the Asian subcontinent, who was not known to have any significant medical illnesses in the past was admitted with unilateral lower limb swelling of three days duration and was subsequently diagnosed to have DVT. He denied recent immobilization, hospitalization or travel. There was no history of trauma, fever, cough, shortness of breath or chest discomfort. He denied having night sweats or weight loss. He was not a smoker and did not consume alcohol. Initial physical examination revealed a tender swollen right lower limb extending from the midthigh to the lower leg. Vital signs and system examination were unremarkable. His initial blood investigation was normal except for a random blood glucose level of $13.7 \mathrm{mmol} / \mathrm{L}$ and elevated C-reactive protein (CRP) of $88.1 \mathrm{mg} / \mathrm{L}$ (normal range 0-5; Table 1). Doppler ultrasound of the affected limb demonstrated extensive DVT involving the right femoral vein and tibial vein (Figures 1 and 2). 


\section{Cureus}

\begin{tabular}{|c|c|c|c|c|}
\hline Group & Detail & Value w/units & Flags & Normal range \\
\hline \multirow{9}{*}{ General hematology } & White blood cells & $6.0 \times 10^{3} / \mu \mathrm{L}$ & & $4.0-10.0$ \\
\hline & Red blood cells & $6.0 \times 10^{6} / \mu \mathrm{L}$ & HI & $4.5-5.5$ \\
\hline & Hemoglobin & 18.3 g/dL & $\mathrm{HI}$ & 13.0-17.0 \\
\hline & Platelet & $147 \times 10^{3} / \mu \mathrm{L}$ & LOW & $150-400$ \\
\hline & Absolute neutrophil count & $4.3 \times 10^{3} / \mu \mathrm{L}$ & & $2.0-7.0$ \\
\hline & Lymphocyte & $0.8 \times 10^{3} / \mu \mathrm{L}$ & LOW & $1.0-3.0$ \\
\hline & Monocyte & $0.9 \times 10^{3} / \mu \mathrm{L}$ & & $0.2-1.0$ \\
\hline & Eosinophil & $0.0 \times 10^{3} / \mu \mathrm{L}$ & & $0.0-0.5$ \\
\hline & Basophil & $0.04 \times 10^{3} / \mu \mathrm{L}$ & & $0.02-0.10$ \\
\hline \multirow{13}{*}{ Blood chemistry } & Procalcitonin & $0.13 \mathrm{ng} / \mathrm{mL}$ & NA & \\
\hline & Bilirubin total & $28 \mu \mathrm{mol} / \mathrm{L}$ & $\mathrm{HI}$ & $0-21$ \\
\hline & Total protein & $80 \mathrm{~g} / \mathrm{L}$ & & $66-87$ \\
\hline & Albumin & $32 \mathrm{~g} / \mathrm{L}$ & LOW & $35-52$ \\
\hline & Alkaline phosphate & $65 \mathrm{U} / \mathrm{L}$ & & $40-129$ \\
\hline & Alanine aminotransferase & $16 \mathrm{U} / \mathrm{L}$ & & $0-41$ \\
\hline & Aspartate aminotransferase & $19 \mathrm{U} / \mathrm{L}$ & & $0-40$ \\
\hline & HbA1C\% & $8.7 \%$ & NA & \\
\hline & Urea & $2.8 \mathrm{mmol} / \mathrm{L}$ & & $2.8-8.1$ \\
\hline & Creatinine & $71 \mu \mathrm{mol} / \mathrm{L}$ & & $62-106$ \\
\hline & Glucose random & $13.7 \mathrm{mmol} / \mathrm{L}$ & $\mathrm{HI}$ & 5.4 \\
\hline & C-reactive protein & $88.1 \mathrm{mg} / \mathrm{L}$ & $\mathrm{HI}$ & $0.0-5.0$ \\
\hline & Lactic acid & $1.6 \mathrm{mmol} / \mathrm{L}$ & & $0.5-2.2$ \\
\hline
\end{tabular}

\section{TABLE 1: Initial laboratory values}

HI: high. 


\section{Cureus}

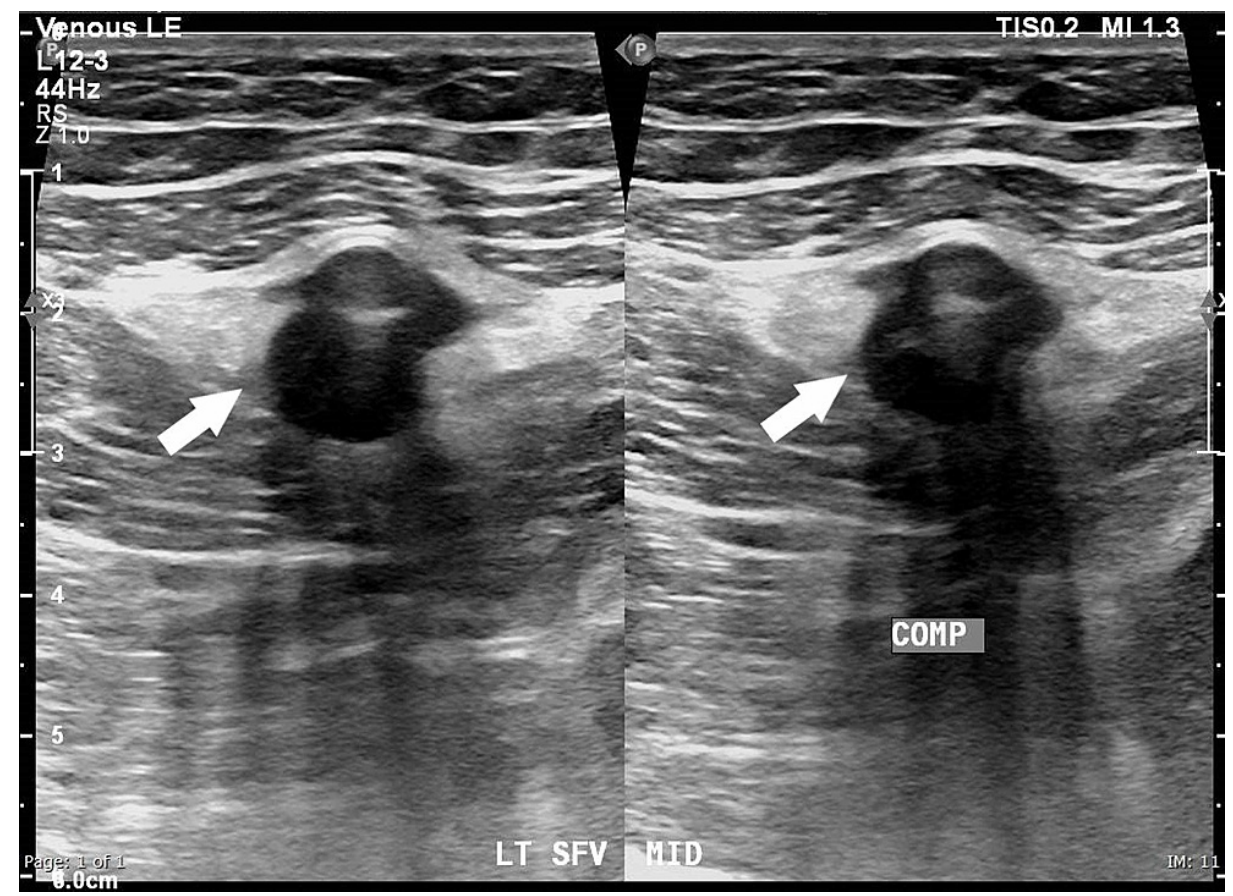

FIGURE 1: Grey-scale ultrasound at the level of the mid-thigh demonstrating non-compressibility of the superficial femoral vein (white arrows)

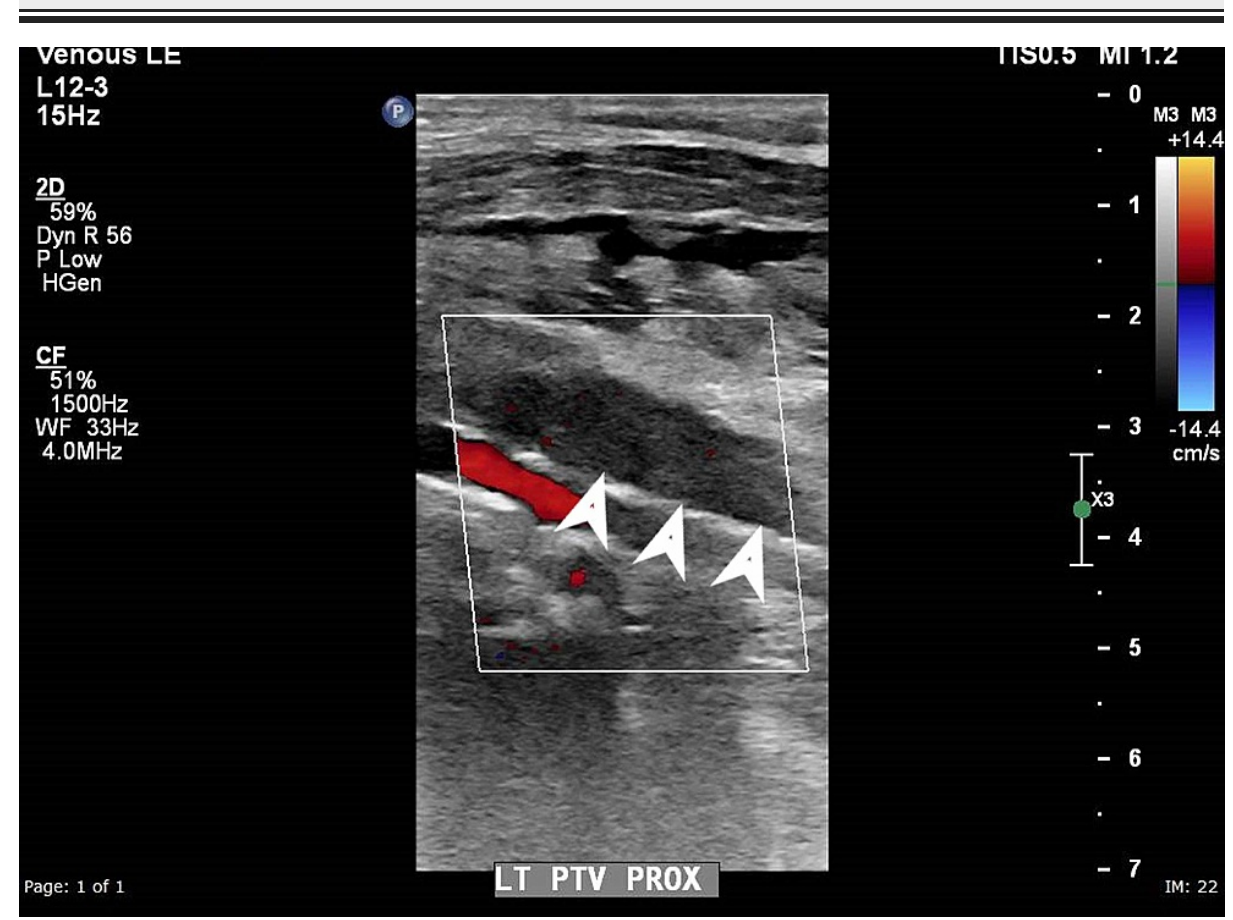

FIGURE 2: Colour Doppler ultrasound at the level of the proximal calf demonstrating absent colour flow in the posterior tibial vein (arrowheads) suggestive of thrombosis

As a part of the evaluation of unprovoked DVT, a chest X-ray was done which showed a non-homogenous opacity of the middle and upper zones of the right lung (Figure 3). The patient underwent a computer tomography (CT) scan of the chest, which revealed PE involving the bifurcation of the right pulmonary artery and segmental branches of right lower lobe arteries and bilateral upper lobe consolidation (Figure 4). In view of newly diagnosed diabetes and upper lobe consolidation, sputum acid-fast bacillus (AFB) was 


\section{Cureus}

requested which turned out to be positive, subsequently, antituberculous treatment (ATT) was started. For thromboembolism, he was initiated on enoxaparin and later switched to warfarin. The warfarin dosage was titrated to attain a therapeutic range of International Normalized Ratio (INR; between 2 and 3). A higher dose of warfarin $(18 \mathrm{mg})$ was required to attain the target INR.

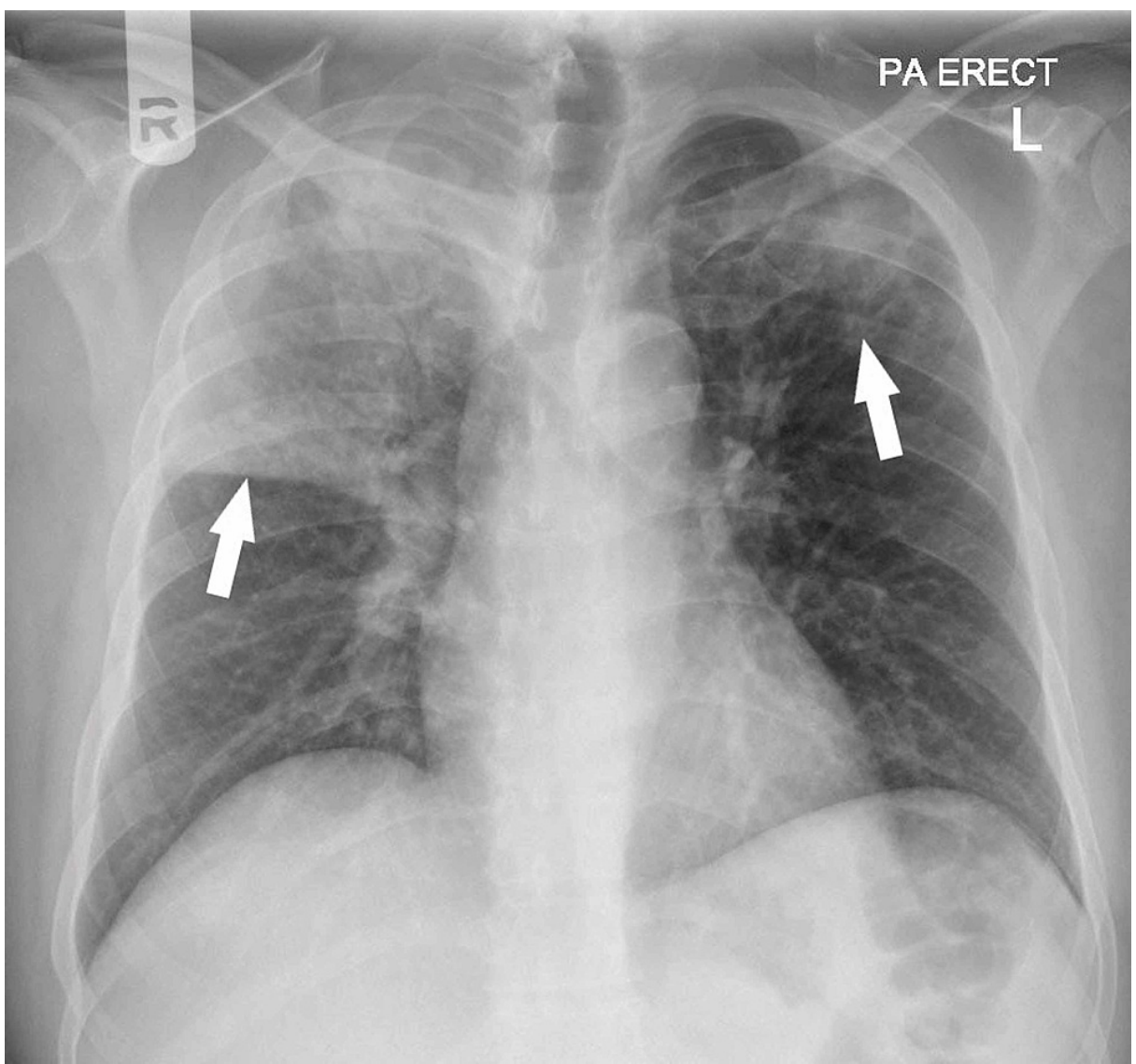

FIGURE 3: Chest X-ray demonstrating bilateral upper lobe consolidation (white arrows), more extensive on the right
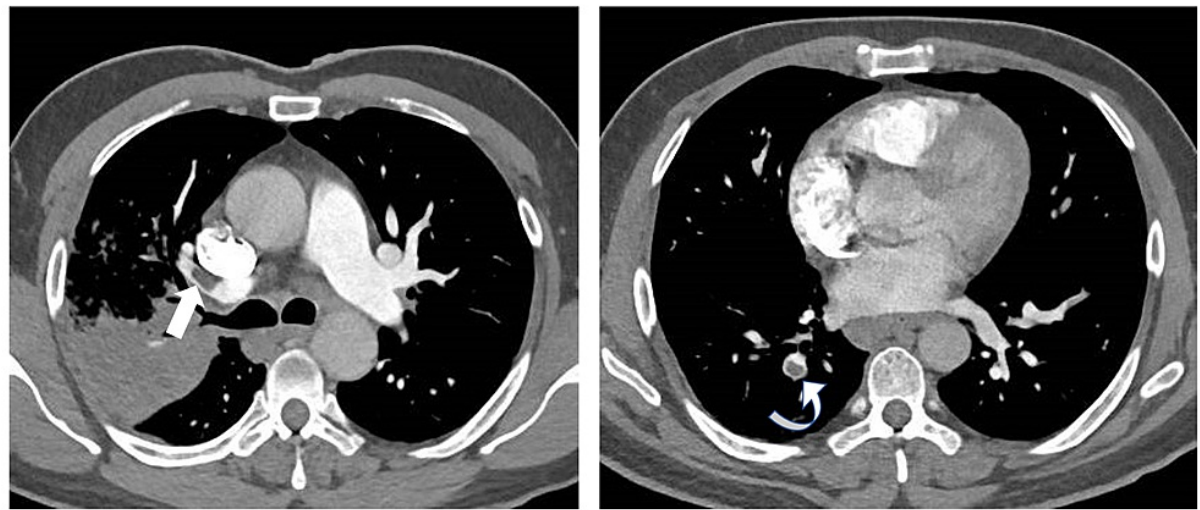

FIGURE 4: CT pulmonary angiogram demonstrates a filling defect in the anterior segmental branch of the right upper lobe pulmonary artery (straight arrow) and posterior basal segmental branch of the right lobe pulmonary artery (curved arrow)

The patient was evaluated for thrombophilia and autoimmune diseases, which were negative (Table 2). He responded well to the first line of ATT medications and the repeat sputum AFB smear was negative after two 


\section{Cureus}

weeks. He was discharged after 24 days of hospitalization. The patient was followed up in the outpatient clinic after 10 weeks. He was asymptomatic. Repeat chest X-ray during follow-up showed resolution of the consolidation (Figure 5).

\begin{tabular}{|c|c|c|c|c|}
\hline Group & Detail & Value w/units & Flags & Normal range \\
\hline Autoimmune diseases & Anticardiolipin Ab lgG & $5.20 \mathrm{GPL}$ & NA & \\
\hline Autoimmune diseases & Anticardiolipin Ab IgG Int & Negative & NA & \\
\hline Autoimmune diseases & Anticardiolipin Ab IgM & $5.70 \mathrm{MPL}$ & NA & \\
\hline Autoimmune diseases & Anticardiolipin Ab lgM Int & Negative & $\mathrm{NA}$ & \\
\hline Autoimmune diseases & ANA CTD Int & Negative & NA & \\
\hline General immunology & C3 & $1.57 \mathrm{gm} / \mathrm{L}$ & & $0.90-1.80$ \\
\hline General immunology & C4 & $0.50 \mathrm{gm} / \mathrm{L}$ & $\mathrm{HI}$ & $0.10-0.40$ \\
\hline Homocysteine plasma & Homocysteine plasma LC-MSMS & $19.9 \mu \mathrm{mol} / \mathrm{L}$ & $\mathrm{HI}$ & 0.0-15.0 \\
\hline Mycobacteriology & Acid-fast bacilli smear & Review result & Review result & \\
\hline Mycobacteriology & Acid-fast bacilli culture & Review result & Review result & \\
\hline Acid-fast bacilli PCR & TB PCR & Positive & ABN & \\
\hline Acid-fast bacilli PCR & MTB & MTB DNA detected & CRIT & \\
\hline Acid-fast bacilli PCR & Rifampicin-resistance & Rifampicin resistance not detected & $\mathrm{NA}$ & \\
\hline
\end{tabular}

\section{TABLE 2: Other investigations}

PCR: polymerase chain reaction, ANA: antinuclear antibodies, CTD: connective tissue diseases, LC: liquid chromatography with tandem mass spectrometry, MTB: Mycobacterium tuberculosis, GPL: immunoglobulin G [IgG] phospholipid units, MPL: immunoglobulin M [IgM] phospholipid units, ABN: abnormal, CRIT: critical.

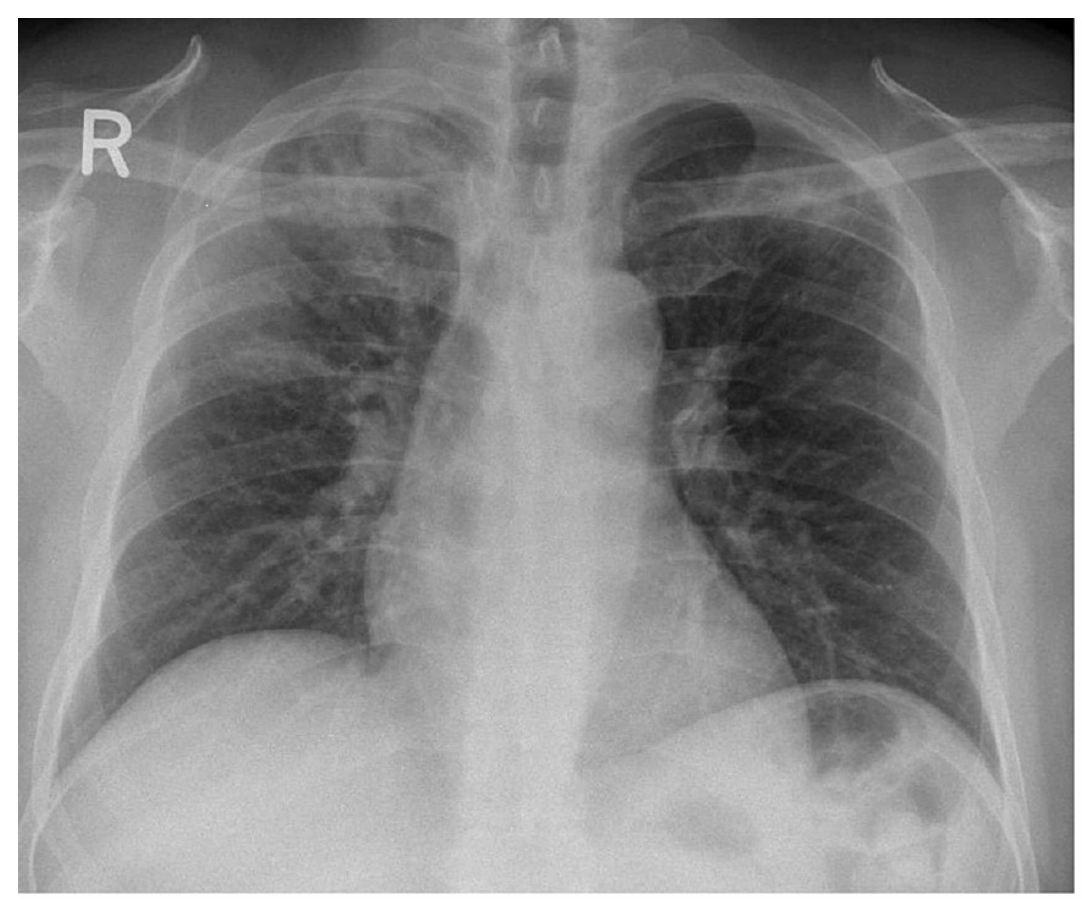

\section{FIGURE 5: Chest X-ray on follow-up shows improvement of the consolidation}




\section{Discussion}

Tuberculosis remains a major public health problem, especially, in developing countries. A wide spectrum of disease presentation and multisystem involvement may sometimes cause a diagnostic dilemma for the treating physician. Thrombogenic potential and vascular complications of tuberculosis are often overlooked when evaluating patients with thromboembolism [1]. The occurrence of PE in patients with tuberculosis was described in the literature as early as 1950. Moran studied autopsy reports of patients with active tuberculosis and reported that $24.3 \%$ had PE [4]. In a report from Vaideeswar and Deshpande, on evaluation of 30 patients with aortic thrombosis, six patients had active tuberculosis [5]. The pathogenesis of thromboembolism in patients with TB can be multifactorial. All three elements of Virchow's triad are activated in patients with tuberculosis. The hypercoagulable state is due to the increased levels of fibrin and platelet hyperactivity. Dysfunction of fibrinolysis also contributes to a hypercoagulable state. Stasis of the blood occurs due to external compression of the blood vessels by lymph nodes or from prolonged immobilization. The third factor of Virchow's triad is the damage to the vascular endothelium due to the ongoing systemic inflammatory processes [6-8].

The time of occurrence of venous thromboembolism can be varied in patients with TB. Robson et al. reported that only 2 of the 35 patients had DVT on admission, similar to our patient and all the rest developed DVT after one week [7]. In another study, Ambrosetti et al. reports the prevalence of DVT in patients with TB as $0.6 \%$ in the initial month of treatment [9]. According to the literature, the occurrence of DVT and PE in patients with TB is uncommon, and the likelihood of both being present in the same patient is even rarer. In a case series by Mohan et al., out of five patients with either DVT or PE in pulmonary tuberculosis, only one had both the entities [3].

During the management of venous thromboembolism in patients with tuberculosis, the enzyme-inducing property of rifampicin which is used as the first line of therapy causes a challenge in attaining therapeutic anticoagulation while using warfarin [10]. Patients often require a higher dose of warfarin as in our patient and prolonged duration of heparin till a therapeutic level of INR is attained.

\section{Conclusions}

Tuberculosis is a common infectious disease in the developing world and can manifest with various pulmonary or extrapulmonary symptoms. Tuberculosis can be considered as an independent risk factor for the development of venous thromboembolism. The etiology for the development of thromboembolism is multifactorial. Early diagnosis and treatment of this serious complication are crucial for a better outcome.

\section{Additional Information}

\section{Disclosures}

Human subjects: Consent was obtained or waived by all participants in this study. Medical Research Center- Hamad Medical Corporation issued approval MRC-04-21-189. Conflicts of interest: In compliance with the ICMJE uniform disclosure form, all authors declare the following: Payment/services info: All authors have declared that no financial support was received from any organization for the submitted work. Financial relationships: All authors have declared that they have no financial relationships at present or within the previous three years with any organizations that might have an interest in the submitted work. Other relationships: All authors have declared that there are no other relationships or activities that could appear to have influenced the submitted work.

\section{References}

1. Houben RM, Dodd PJ: The global burden of latent tuberculosis infection: a re-estimation using mathematical modelling. PLoS Med. 2016, 13:1002152. 10.1371/journal.pmed.1002152

2. El Fekih L, Oueslati I, Hassene H, Fenniche S, Belhabib D, Megdiche ML: Association thromboses veineuses profondes avec tuberculose pulmonaire. Tunis Med. 2009, 87:328-9.

3. Mohan B, Kashyap A, Whig J, Mahajan V: Pulmonary embolism in cases of pulmonary tuberculosis: a unique entity. Indian J Tuberc. 2011, 58:84-7. 10.29328/journal.jfsr.1001018

4. Moran TJ: Autopsy incidence of pulmonary embolism in tuberculosis . Dis Chest. 1950, 18:171-3. 10.1378/chest.18.2.171

5. Vaideeswar P, Deshpande JR: Non-atherosclerotic aorto-arterial thrombosis: a study of 30 cases at autopsy . J Postgrad Med. 2001, 47:8-14.

6. Zahn DW, Peirce CT: Venous thrombosis and pulmonary embolism in tuberculosis . Am J Med. 1948, 5:71628. 10.1016/0002-9343(48)90149-1

7. Robson SC, White NW, Aronson I, Woollgar R, Goodman H, Jacobs P: Acute-phase response and the hypercoagulable state in pulmonary tuberculosis. Br J Haematol. 1996, 93:943-9. 10.1046/j.13652141.1996.d01-1722.x

8. Turken O, Kunter E, Sezer M, et al.: Hemostatic changes in active pulmonary tuberculosis . Int J Tuberc Lung Dis. 2002, 6:927-32.

9. Ambrosetti M, Ferrarese M, Codecasa LR, et al.: Incidence of venous thromboembolism in tuberculosis patients. Respiration. 2006, 73:396. 10:1159/000091188

10. Kwas H, Habibech S, Zendah I, Elmjendel I, Ghedira H: Pulmonary embolism and tuberculosis. Asian 


\section{Cureus}

Cardiovasc Thorac Ann. 2014, 22:487-90. 10.1177/0218492313485071 